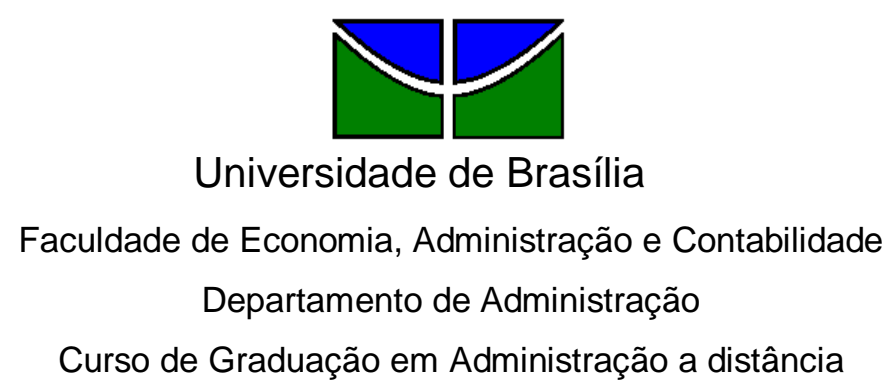

ALYSSANDRA CORREA DE MORAIS DOS SANTOS

\title{
POLÍTICA DE ATENDIMENTO AO CIDADÃO: Um estudo de caso na Organização das Centrais de Atendimento (OCA)
}

Rio Branco/AC 


\section{ALYSSANDRA CORREA DE MORAIS DOS SANTOS}

\section{POLÍTICA DE ATENDIMENTO AO CIDADÃO: Um estudo de caso na Organização das Centrais de Atendimento (OCA)}

Monografia apresentada a Universidade de Brasília (UnB) como requisito parcial para obtenção do grau de Bacharel em Administração.

Professor Supervisor: Dr. José Matias-Pereira

Professor Tutor: Esp. Josias Rodrigues Alves

Rio Branco / AC

2011 
Santos, Alyssandra Correa de Morais.

Política de Atendimento ao Cidadão: Um estudo de caso na OCA Organização das Centrais de Atendimento /Alyssandra Correa de $52 \mathrm{f} .:$ il. Morais dos Santos. - Acre 2011

Monografia (bacharelado) - Universidade de Brasília, Departamento de Administração - EaD, 2011

Orientador: Prof. Esp. Josias Rodrigues Alves, Departamento de Administração.

1. Politica de atendimento ao cidadão. 2. Entidades Fechadas de Previdência Complementar. 3. Aplicação de Recursos das Entidades Fechadas de Previdência Complementar. I. Título. 


\section{ALYSSANDRA CORREA DE MORAIS DOS SANTOS}

\section{POLÍTICA DE ATENDIMENTO AO CIDADÃO: Um estudo de caso na Organização das Centrais de Atendimento (OCA)}

A Comissão Examinadora, abaixo identificada, aprova o Trabalho de Conclusão do Curso de Administração da Universidade de Brasília da aluna

Alyssandra Correa de Morais dos Santos

Esp. Josias Rodrigues Alves

Professor-Orientador

Dra Marina Figueiredo Moreira

Professor-Examinador
Titulação, nome completo

Professor-Examinador

Rio Branco, AC, 03 de dezembro de 2011. 
Dedico esse trabalho a Deus que me permitiu chegar ate aqui, e a minha vó, Carlota Pereira de Morais (in memorian), pois com tanta presteza, carinho e dedicação ensinou-me os primeiros degraus do conhecimento e da sabedoria. Seringueira e analfabeta, lutou pela construção do Acre e do Brasil, durante o surto da borracha na II Guerra Mundial. Sou privilegiada por ser sua neta, por isso, a ela toda minha gratidão. 


\section{AGRADECIMENTOS}

- Agradeço aos idealizadores desse projeto, aos quais sem eles não teria sido possível a conclusão dessa graduação.

- Aos queridos tutores pelo carinho, paciência e dedicação, em especial a Esp. Tutora e professora Alessandra Lisboa.

- Ao nosso orientador, Esp. Josias Rodrigues Alves, e coordenador, Dr. José MatiasPereira, pela paciência e cuidado para que pudéssemos fazer sempre o nosso melhor.

- Agradeço a minha família - meu esposo Ladislau, que esteve sempre ao meu lado me ajudando e acolhendo nas minhas dificuldades, e minhas filhas Alyne Rebeca e Alana Raabe, pela paciência de me suportar nos momentos de intenso estudo em que deixei de estar com elas pra resolver as atividades da semana, nos muitos fins de semana em frente ao computador.

- Ao meu querido pai por me ter dado a vida, por ser meu orgulho e exemplo.

- Agradeço ao Esp. Henri, por me ceder suas recentes pesquisas de campo e pela calorosa recepção no TCE, orientação e suporte;

- Aos Gestores da OCA, por permitirem a realização deste trabalho.

- A todos os acrianos e ao nosso Estado por ser nosso motivo de mui grande orgulho.

- Em fim, aos colegas de graduação que estiveram lado a lado nessa jornada 
"Se algum de vocês quer ser o maior, seja o menor, seja o último, seja aquele que serve".

(Jesus de Nazaré) 


\section{RESUMO}

Um Estado moderno e capaz de atender aos anseios da sociedade a qual se propõe organizar depende, fundamentalmente de cidadãos conscientes, que participam das decisões políticas e da implementação de políticas públicas, visando um maior controle social das ações do Estado, em especial, dos serviços por este diretamente prestado à comunidade. Nessa trilha, importantes ações vêm sendo gradativamente executadas pelos governos objetivando reformar o Estado para um moderno patamar de administração, esta, mais preocupada com a desburocratização dos serviços oferecidos. E mais: alcance uma gestão no modelo gerencial, estratégica e por objetivos. Essas reformas clamam eficiência, eficácia e efetividade dos serviços públicos prestados, através do fortalecimento da cidadania com ênfase nos resultados, orientação cliente-cidadão-patrão, garantido com isso maior governança e governabilidade. Esse trabalho teve como foco principal a verificação e analise da política de atendimento ao cidadão através de um estudo de caso na OCA (Organização em Centros de Atendimento). Para que fosse possível esse estudo, foi feito primeiramente um levantamento prévio da literatura bibliográfica na contemporaneidade à luz da administração Pública no Brasil, através de observação e análise documental. Além de pesquisa estruturada com gerente e administração, para que pudéssemos compreender o novo modelo adotado pelo Governo do Acre, no tocante à prestação de serviços públicos à população, verificando os entraves e propondo avanços para os demais municípios.

Palavras-chave: Atendimento ao Cidadão. Efetividade. Controle social. Satisfação. 


\section{LISTA DE ABREVIATURAS E SIGLAS}

BM - Balcão Multisserviços

GESPUBLICA - Programa Nacional de Gestão Pública e Desburocratização

MARE - Ministério da Administração Federal e Reforma do Estado

OCA - Organização em Centro de Atendimento

OCDE - Organizações para Cooperação e o Desenvolvimento Econômico

OSCIPS - Organizações da Sociedade Civil de Interesse Público 


\section{SUMÁRIO}

1 INTRODUÇÃO

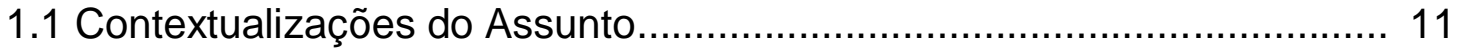

1.2 Formulação do problema.............................................................. 11

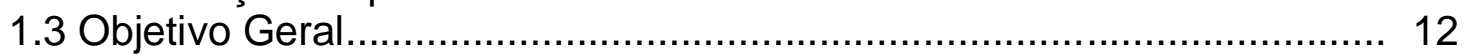

1.4 Objetivos Específicos................................................................ 13

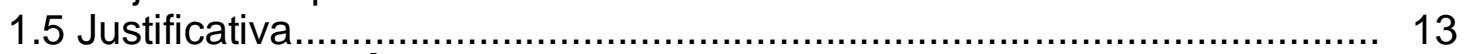

2 REFERENCIAL TEÓRICO …............................................................ 14

2.1 Estado e Administração Pública........................................................ 14

2.1.1 Conceito de Estado.............................................................. 15

2.1.2 O Estado e seus três elementos.............................................. 15

2.1.3 O papel do Estado no mundo contemporâneo............................. 17

2.1.4 Conceitos de administração Pública........................................... 18

2.2 Histórico e modelo de Administração Pública no Brasil.......................... 18

2.2.1 Administração Pública Patrimonialista...................................... 18

2.2.2 Administração Pública Burocrática ............................................. 19

2.2.3 Administração Pública Gerencial e o foco no cidadão .................. 19

2.3 A reforma da Gestão Pública de 1995 .............................................. 20

$2.4 \mathrm{O}$ surgimento das Centrais de Atendimento Integrado no Brasil ............ 21

2.4.1 Centrais de Atendimento ao Cidadão em outros Estados ............ 23

2.4.1.1 O Poupa-Tempo em São Paulo ..................................... 23

2.4.1.2 O Na Hora no Distrito Federal ........................................ 23

2.4.1.3 O Vapt-Vupt na Bahia .................................................. 24

2.4.2 Atendimento integrado: o que se espera do governo ................... 25

2.43 Balcão Multisserviços.............................................................. 26

3 MÉTODOS E TÉCNICAS DE PESQUISA ………................................ 29

3.1 Caracterização da organização, setor ou área.................................... 30

3.2 Participantes do estudo........................................................... 30

3.3 Caracterização dos instrumentos de pesquisa..................................... 31

3.4 Procedimentos de coleta e de análise de dados................................. 32

4 RESULTADOS E DISCUSSÃO.......................................................... 33

4.1 Atendimento Efetivado na OCA .................................................... 36

4..2 Distribuição de funcionários na OCA …........................................... 37

5 CONSIDERAÇÕES E RECOMENDAÇÕES ………............................. 38

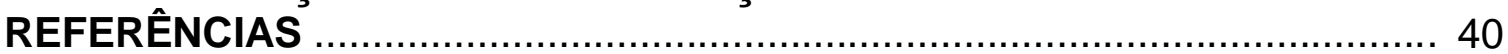

APÊNDICES ...-Modelo de entrevista......................................................... 43

Apêndice A - Centrais de Atendimento X............................................ 46

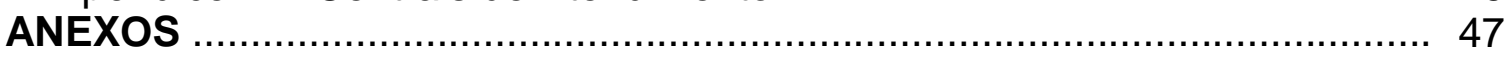

Anexo A - Política de Atendimento ao Cidadão no Acre................................ 52 


\section{INTRODUÇÃO}

\subsection{Contextualizações do Assunto}

A Administração Pública vem buscando adotar novos modelos e padrões de excelência no atendimento, cujo foco é o cidadão como cliente. Por isso vem implementando ações no intuito de ampliar os canais de relacionamento e acesso aos serviços públicos pelo cidadão-usuário.

Este processo de transformações no cenário mundial e de reformas no seio da administração pública tem seu auge a partir do surgimento da forma gerencial de administrar, própria da iniciativa privada, e que passou a integrar-se ao comportamento do administrador público para poder melhor atender as necessidades e expectativas do novo cidadão-cliente.

Estas novas demandas e necessidades do Estado foram logo percebidas por Bresser Pereira, quando da criação do Plano Diretor da Reforma do Aparelho do Estado, a conhecida Reforma Gerencial de 1995. Esta era voltada para o gerenciamento da eficiência do desempenho da máquina administrativa estatal. Isto se tornou imprescindível para a descentralização das ações do estado e legitimação do administrador público ante o cidadão. Nesse sentido, Bresser Pereira (1996, apud 2009, p. 53) argumenta que o novo papel do Estado, com vista a atender a estas demandas, é o de facilitar a competitividade internacional, o que pode ser conseguido mediante melhoria dos seus sistemas de gestão para uma ação mais efetiva e eficiente em beneficio da sociedade A criação das centrais de Atendimento integrado deriva, em parte, do Plano diretor da Reforma do Estado, lançado pelo governo Federal em 1995.

A partir do plano, foram definidos objetivos e diretrizes para a administração pública brasileira e visando a adoção de novas formas de flexibilidade e descentralização para a melhoria das práticas gerenciais, focando o cidadão como o 
principal beneficiário dos serviços públicos, portanto, cliente. Bresser Pereira, no Plano Diretor de Reforma do Estado, enfatiza:

É preciso, agora, dar um salto adiante, no sentido de uma administração pública que chamaria de 'gerencial', baseada em conceitos atuais de administração e eficiência, voltada para o controle de resultados e descentralizada para poder chegar ao cidadão, que, numa sociedade democrática, é quem dá legitimidade às instituições e que, portanto, se torna 'cliente privilegiado' dos serviços prestados pelo Estado.

A reforma administrativa do Estado brasileiro, promovida pelo então Ministério da Administração Federal e Reforma do Estado (MARE), em 1995, visou modernizar sua gestão, propondo, para tanto, um modelo gerencial de gestão por objetivos e estabeleceu estratégias para a modernização da administração pública. A reforma, segundo o MARE, fundamentou-se em uma administração pública mais eficiente, voltada para o fortalecimento da cidadania, cujos pressupostos foram os de maior qualidade, otimização dos recursos, ênfase nos resultados, orientação clientecidadão via controle social, maior governança e governabilidade. No bojo dela, ocorreu uma redefinição do papel do Estado, repassando a terceiros a responsabilidade direta da prestação de bens e serviços, fortalecendo, em contrapartida, seu papel como promotor, regulador e fiscalizador da prestação dos serviços

Matias-Pereira (2009, p. 108) entende que:

[...] a capacidade da administração pública de realizar e obter resultados em benefício da sociedade depende em geral do modo como se encontra estruturada, e tem como exemplo o Brasil, que tem como base de apoio uma estrutura pesada, burocrática e centralizada, incapaz de responder, enquanto organização, às demandas e aos desafios da modernidade.

Pensando nessa nova visão de gestão, mais recentemente foi instituído o Programa Nacional de Gestão Publica e Desburocratização - GESPÚBLICA, com o fim de modernizar ainda mais a máquina pública e simplificar a vida do cidadão, informando-o, através da Carta de Serviço, a qual, além de servir como portfólio dos produtos/serviços oferecidos é um instrumento que estimula sua participação no acesso aos serviços e, sobretudo, no controle social. 
Para a implantação de uma gestão de caráter gerencial, e como diria, respondendo a essas demandas como à modernidade, um dos grandes desafios do Estado, que foram direcionados pelo Ministério do Planejamento do Governo Federal através de "Carta ao Cidadão", é o de inovar, qualitativamente, nas ações direcionadas ao cidadão, visando facilitar a vida dele e da sociedade de modo geral.

Por isso, o Estado do Acre busca esse melhoramento da máquina Pública, em observância as estas novas políticas e, em especial, torna-se adesa ao GESPUBLICA, quebrando paradigmas.

Com isto, o cidadão passa a ser agente da Reforma do Estado, com o papel de fiscalizar os serviços e atividades da Administração Pública, passando a ter o direito de questionar a qualidade dos serviços ofertados diretamente pelo Estado ou por terceiros por ele contratados por este.

A efetivação deste controle social é indispensável para a melhoria contínua da qualidade dos serviços prestados pelas instituições públicas como um todo.

\subsection{Formulação do problema}

A Política de Atendimento desenvolvida pela OCA é efetiva e contribui para a eficiência da Administração Pública? Até que ponto, a OCA pode ser considerada uma referência em atendimento ao cidadão e como um modelo apto a ser expandido para outros municípios?

\subsection{Objetivo Geral}

Conhecer a Política Pública de Atendimento ao Cidadão desenvolvida na OCA e avaliar se os resultados institucionais alcançadas estão alinhados ao modelo de gestão pública estadual e passíveis de ser reproduzidas em unidades de atendimento de outros municípios do Acre. 


\subsection{Objetivos Específicos}

- Apresentar, de forma estruturada, o modelo de atendimento desenvolvido na OCA, incluído seus objetivos.

- Descrever os principais serviços disponibilizados pela Organização das Centrais de Atendimento - OCA.

- Avaliar os resultados alcançados, frente aos os objetivos governamentais para que sirvam de estudo na ampliação da política de atendimento em outros municípios do Acre.

\subsection{Justificativa}

A partir da constituição cidadã de 1988 houve uma crescente preocupação do Estado brasileiro com o cidadão, seus direitos e suas necessidades. Posteriormente, o governo avançou no intuito de descentralizar e desburocratizar os serviços públicos e de melhorar a relação do Estado com a sociedade.

Este trabalho de pesquisa tem importância relevante para o Estado do Acre, pois visam conferir os resultados da nova gestão de atendimento implantada recentemente.

Novos valores, entre servidores públicos e o cidadão, vêm sendo desenvolvidos, e o Governo do Acre busca modernizar a administração pública nesse sentido.

Estudar as atividades desenvolvidas na OCA é fundamental para conhecer a aplicabilidade e efetividade da política de atendimento efetivada no Estado.

A proposta de um estudo de caso visa saber até que ponto a OCA vem sendo eficiente e eficaz na promoção da cidadania e na correlação com o novo modelo de administração pública que visa à integração, desburocratização e excelência no atendimento. 


\section{REFERENCIAL TEÓRICO}

Nesta seção do trabalho serão apresentados os principais conceitos sobre o estado e administração Pública buscando resgatar o papel do estado frente à sociedade e entender a evolução histórica da administração pública no Brasil, de fundamental importância para situar o leitor quanto à extensão da abordagem que pretende dar à pesquisa, e assim, torne mais fácil sua compreensão nas análises dos dados coletados e analisados.

Primeiro será abordado sobre o conceito do Estado e os seus elementos, logo depois o papel do Estado na contemporaneidade

Em seguida, serão apresentados o histórico e modelos da administração pública no Brasil e a reforma do Estado em 1995.

Por fim, será abordado sobre o surgimento das Centrais de Atendimento integrado e os principais centros integrados no Brasil e o que o se espera do governo.

\subsection{Estado e Administração Pública}

\subsubsection{Conceito de Estado}

A denominação "Estado" enquanto sinônimo de país foi dada desde a Antiguidade por filósofos como Maquiavel, Thomas Hobbes e Montesquieu. Eles estudaram o poder político para organizar o país e administrá-lo com eficiência Bonavides (1997 apud PALASSI, p. 27)

Bastos (1988, apud PALASSI, p. 28) nos diz que o Estado (país) é uma associação humana (povo) que mora em determinado lugar (território), sob o comando de um administrador público (governo) que não se submete a qualquer outro Estado (soberania). O país é soberano por que tem poder decisório para 
conduzir seus rumos de acordo com a vontade de seu povo. Dessa forma o país pode agir de acordo com a vontade de seus integrantes. E ao assim fazer, constrói leis conforme seus códigos de conduta social e administra suas instituições públicas conforme a vontade de seu povo.

\subsubsection{O Estado e seus três elementos}

O Estado é formado por três elementos: Povo, Território, Governo Soberano, a seguir definido:

i. Povo: elemento humano ou conjunto de pessoas que habita um país soberano;

ii. Território: elemento geográfico ou base física onde mora o povo; e

iii. Governo Soberano: autoridades constituídas para administrar o país. Governo é o conjunto de funções pelas quais é assegurado o funcionamento daquele país.

\subsubsection{O papel do Estado no mundo contemporâneo.}

Segundo Matias-Perreira (2010 p.5) em Curso de Administração Pública: foco nas instituições e ações governamentais, "o objetivo primordial do Estado é a busca pelo bem-comum que segundo os teóricos que fizeram essa analise explica-se em três vertentes que seriam: O bem-estar, a segurança e a justiça”. Por isso no estudo da administração Pública temos por primordial objetivo as melhores práticas administrativas do governo em busca de garantir o acesso das reais necessidades do povo, por o mesmo ser o seu representante legal, é deve melhor servi os interesses da população ao qual o legitima.

Atualmente há uma crescente demanda por qualidade nos serviços prestados pelo estado ao cidadão, isso se dar pela relação que há entre o poder político e o poder econômico e nem um deles funciona independente, pois sem o mesmo o povo 
não exerce de fato a sua cidadania, para tanto é necessário haver participação social e transparência nas ações governamentais e ainda compromisso por uma gestão que prime pela promoção da pessoa humana, aqui o povo prevalece sobre o individuo o particular. Para Matias-Perreira (2010).

O objetivo primordial da Administração Pública é promoção da pessoa humana e do seu desenvolvimento integral em liberdade. Para isso deve atuar de maneira efetiva para viabilizar e garantir os direitos do cidadão, os quais estão consagrados na constituição. (MATIAS-PEREIRA, 2010, p. 2)

De acordo com Palassi (2007, p. 49), a reforma administrativa está atrelada à reforma do Estado, sendo que ambas são distintas entre si. A reforma do Estado está voltada para o crescimento econômico baseada em reforma previdenciária, fiscal e tributária, enquanto que a reforma administrativa são políticas voltadas para a retomada da performance e qualidade dos serviços públicos.

A Reforma do Estado deve ter como principal objetivo a consolidação do processo democrático, a estabilidade econômica e o desenvolvimento sustentável com justiça social porque redefine todas as relações do Estado com a sociedade.

De acordo com Matias-Pereira (2009) a reforma e a modernização do estado é um complexo processo de transição das estruturas políticas, econômicas e administrativas, podendo-se inferir dessa afirmação que a reforma do Estado abarca a reforma administrativa. Ele afirma que a corrupção é um fenômeno que enfraquece a democracia, a confiança no estado, a legitimidade dos governos e a moral pública. Por tudo isso, deve-se observar o maior rigor na reforma de um Estado, buscando sempre a transparência acima de tudo.

Além disso, deve ter a participação efetiva da população, como fiscal das autoridades competentes para que estas não incorram em crimes contra a administração pública, e se isso vier a ocorrer que os responsáveis sejam punidos com todos os rigores da lei.

A prática da democracia deve ser baseada na ética e na transparência na condução dos negócios públicos. Para isso, devem ser criados instrumentos de controle que possibilitem ao cidadão acompanhar todos os atos do poder público. Eficiência e democracia são elementos essenciais da sociedade contemporânea e, 
por isso, devem ser tidas como primordiais no desenvolvimento de um Estado moderno, voltado para o atendimento das demandas sociais.

\subsubsection{Conceitos de administração Pública}

Para Alexandrino e Paulo (2010, p.18), a noção de Administração Pública pode ser visualizada em sentido amplo ou em sentido estrito.

No sentido amplo, a expressão abrange tanto os órgãos governamentais (Governo), aos quais cabe traçar os planos e diretrizes de ações quanto os órgãos administrativos, subordinados, de execução (Administração Pública em sentido estrito). Administração Pública em sentido amplo, portanto, compreende tanto a função política, que estabelece as diretrizes governamentais, quanto à função administrativa, que as executa. (ALEXANDRINO; PAULO; 2010 p.18).

O conceito de Administração Pública em sentido estrito não alcança a função política de Governo, de fixação de planos e diretrizes governamentais, mas tãosomente a função propriamente administrativa, de execução de atividades administrativas.

Administração pública é, portanto, o conjunto de órgãos criados pelo governo e geridos por administradores para atender às necessidades do povo. Cada órgão tem uma função especializada, e o conjunto de órgãos ou pessoas jurídicas forma o serviço público.

A Administração pública realiza serviços visando satisfazer às necessidades da coletividade (povo), que é o elemento mantenedor do Estado através da contribuição de impostos. Esta contribuição deve ser retribuída ao povo através de bens e serviços. A gestão desses bens e serviços deve ser feita por administradores públicos comprometidos em servir à comunidade. Logo, o governo, através do poder Legislativo, cria um conjunto de leis para reger a atuação dos seus administradores.

O administrador público tem em sua gestão a responsabilidade de gerir interesses dos cidadãos e as aspirações da comunidade. 
Dessa forma, enquanto o setor privado é regido pelo mercado e o lucro, a administração pública não pode ser compreendida fora dos princípios do poder e da legitimidade. Isso faz com que a cidadania assuma uma importância infinitamente maior no setor público, onde o "cidadão-cliente é um cidadão-cidadão, um cidadão pleno, que é o objeto dos serviços públicos e também seu sujeito, na medida em que se torna partícipe na formação das políticas públicas e na avaliação dos resultados" (BRESSER-PEREIRA, 1999, p. 118).

\subsection{Histórico e modelo de Administração Pública no Brasil}

A seguir são apresentados os três modelo de Administração Pública, no contexto tratado, Patrimonialista, Burocrática e Gerencial.

\subsubsection{Administração Pública Patrimonialista}

Era um modelo próprio da monarquia absolutas, em que o patrimônio do rei se confundia com o patrimônio Público. O Estado era considerado propriedade do rei. O tesouro real seria o tesouro público, numa clara confusão de público e privado, Uma confusão religiosa do exercício da autoridade real associava o rei, investido de poder pela providência divina, à imagem de protetor e proprietário de seus súbitos que deveriam lealdade a ele, não à nação.

Essa forma de administração mostrou-se incompatível com a lógica e as demandas de uma sociedade civil, estruturada, urbana e uma economia de mercado. Bresser-Pereira (1996, p.4), procura esclarecer por que esse modelo de administração não convive com a sociedade industrial moderna: "É essencial para o capitalismo", escreve o autor, "a clara separação entre o Estado e o mercado; a democracia só pode existir quando a sociedade civil, formada por cidadãos, distingue-se do Estado ao mesmo tempo em que o controla".

Nesse contexto, de forma progressiva, a evolução do capitalismo industrial tende a tronar obsoleta e insustentável essa forma de administração e a buscar a 
constituição de outra forma de administração pública que partisse de uma separação entre o espaço público e privado e o domínio do político e do técnico.

\subsubsection{Administração Pública Burocrática}

A Administração Pública burocrática nasce na segunda metade do século XIX, com o objetivo de combater a corrupção e o nepotismo patrimonialista. Pregava os princípios do desenvolvimento, da profissionalização, idéia de careira pública, hierarquia funcional, impessoalidade, formalismo; tudo cominava no poder legal, colocando a priori as metas de acabarem com o nepotismo e com a corrupção. Para isso, torna-se necessário o controle rígido dos processos e do ingresso à careira pública, com as regras da admissão, controle nas compras, visando evitar abusos, ineficiência e incapacidade. A administração burocrática tornou-se inadequada aos interesses da população, visando que suas regras passaram a ser sobrepor aos interesses da sociedade. (MATIAS-PEREIRA, 2010, p. 113).

A complexidade das novas tarefas atribuídas ao poder público no Estado social - como a prestação de diversos serviços públicos, como educação, saúde, a regulação de atividades possíveis de externalidades, como a vigilância sanitária, a proteção do meio ambiente, as diferentes políticas sociais voltadas ao combate às desigualdades - tornou indispensável à ideia da eficiência da máquina pública, ao qual, para tanto, deveria levar em conta seus custos, ter uma administração menos hierárquica e mais flexível e, sobretudo, buscar a melhoria da qualidade dos serviços prestado ao cidadão.

\subsubsection{Administração Pública Gerencial e o foco no cidadão}

A Nova Administração Pública denominada por Bresser-Pereira como administração Gerencial, deriva-se do que pode ser chamado de reforma de segunda geração, por incluir não apenas medidas de contenção fiscal, mas, sobretudo, o fortalecimento do gerenciamento público, de instituições de controle e 
imputação de resultados e estruturas mais flexíveis em que o cidadão pode ser perceber e ter voz, como usuário de serviços públicos e contribuinte.

A implementação da Nova Gestão Pública, voltada para o cidadão, iniciou-se na a partir dos anos 80 e teve origem nos países da OCDE (Organizações para Cooperação e o Desenvolvimento Econômico), principalmente na Inglaterra, sob a administração de Margaret Thatcher junto com um forte discurso de defesa do estado mínimo. O que ela percebia era uma economia britânica em crise e um serviço público letárgico. (Thatcher,,1993, apud, COSTIN 2010,p. 33 ).

Nos anos 90 essa reforma se estendeu aos EUA e Brasil Dentro do contexto democrático, a administração gerencial tornou-se um instrumento de gestão que visa modernizar o Estado e torna a mais eficiente voltada ao cidadão usuário. (COUTINHO, 2000, p. 1)

Para Costin (2010, p.34), as características mais relevantes da administração pública gerencial e sua evolução pode ser sintetizada como:

\begin{abstract}
Sistema de gestão e controle centrados em resultados e não mais em procedimentos; Maior autonomia gerencial do administrador público; Avaliação e divulgação de efeitos/produtos e resultados tornam-se chaves para identificar políticas e serviços públicos efetivos; Estrutura de poder menos centralizados e hierárquico, permitindo maior rapidez e economia na prestação de serviços e participação dos usuários; Contratualização de resultados a serem alcançados, com explicitação mais clara de aportes para sua realização; Incentivos ao desempenho superior, inclusive financeiro; Criação de novas figuras institucionais para a realização de serviços que não configuram atividades exclusivas de Estados, como PPP (Parcerias Público-Privado) e organizações sociais e Oscips (Organizações da Sociedade Civil de Interesse Público) que podem estabelecer parcerias com o poder púbico.
\end{abstract}

\title{
2.3 A reforma da Gestão Pública de 1995
}

A reforma gerencial de 1995, como as demais reformas dessa natureza respondeu ao grande aumento do tamanho do Estado que implicou suas transformações em um Estado Social ao tornar a administração publica ou a organização do Estado mais eficiente, legitimou os grandes serviços sociais de educação, saúde, previdência e assistência social que, a partir da revolução de 1930 e da transição democrática de 1995, resultaram na transformação do regime político 
oligárquico liberal I brasileiro em um regime democrático e social. (COSTIN, 2010, p. 74)

Entre os países em desenvolvimento, o Brasil foi o primeiro a iniciar uma reforma gerencial, no Governo de Fernando Henrique Cardoso, através do dirigente da Secretária da Administração Federal - Bresser-Pereira

Hoje no Brasil quando se pensa em reforma administrativa, quando se busca o aparelho do Estado mais eficiente, mais capaz de prestar ou financiar serviços sociais, culturais e científicos com baixos custos e boa qualidade, pensa-se em reforma ou da gestão publica.

A reforma Gerencial foi construída por dois documentos básicos: o Plano Diretor da Reforma do Aparelho do Estado e a Emenda Constitucional 19 aprovada em abril de 1998, depois de três anos de debates.

\subsection{O surgimento das Centrais de Atendimento Integrado no Brasil}

A criação das centrais de Atendimento integrado deriva, em parte, do Plano diretor da Reforma do Estado, lançado pelo governo Federal em 1995.

Através desse plano foram definidas objetivos e diretrizes para a administração pública brasileira e visando a adoção de novas formas de flexibilidade e descentralização para a melhoria das práticas gerenciais, focando o cidadão como o principal beneficiário dos serviços públicos, portanto, cliente. Bresser Pereira, no Plano Diretor de Reforma do Estado, enfatiza:

É preciso, agora, dar um salto adiante, no sentido de uma administração pública que chamaria de 'gerencial', baseada em conceitos atuais de administração e eficiência, voltada para 0 controle de resultados e descentralizada para poder chegar ao cidadão, que, numa sociedade democrática, é quem dá legitimidade às instituições e que, portanto, se torna 'cliente privilegiado' dos serviços prestados pelo Estado.

Por outro lado MATIAS-PEREIRA (2009) afirma que:

[...] a capacidade da administração pública de realizar e obter resultados em benefício da sociedade depende em geral do modo como se encontra estruturada, e tem como exemplo o Brasil, que tem como base de apoio uma estrutura pesada, burocrática e 
centralizada, incapaz de responder, enquanto organização, às demandas e aos desafios da modernidade.

Para a implantação de uma gestão de caráter gerencial, e como diria, respondendo a essas demandas como à modernidade, um dos grandes desafios do Estado, que foram direcionados pelo Ministério do Planejamento do Governo Federal através de "Carta ao Cidadão", é o de inovar, qualitativamente, nas ações direcionadas ao cidadão, visando facilitar a vida dele e da sociedade de modo geral.

Por isso, o Estado do Acre busca esse melhoramento da máquina Pública, em observância as estas novas políticas e, em especial, torna-se adesa ao GESPUBLICA, quebrando paradigmas.

As averiguações que deveriam ser necessárias para essa implementação e melhora da qualidade do atendimento, é citada na Carta de Serviço da Secretaria de Gestão do Ministério do Planejamento:

- É imperativo mobilizar e sensibilizar as organizações públicas para a melhoria da qualidade do atendimento prestado. Verifica-se ainda, que a participação efetiva dos cidadãos na melhoria dos serviços oferecidos pelo setor público encontra-se diluída, tendo em vista alguns fatores, tais como:

- A ausência de eficientes e eficazes instrumentos institucionais de controle direto por parte dos cidadãos sobre os administradores públicos.

- A falta de informações adequadas que facilitem o acesso do cidadão aos serviços públicos.

- O não reconhecimento do cidadão como o principal beneficiário das melhorias dos serviços públicos oferecidos.

Para tanto, cabe a cada Estado se responsabilizar pela implementação dessa política, assim como se comprometer com o bom funcionamento dos seus serviços de forma a permitir que o cidadão se torne participante e satisfeito com os serviços oferecido pelo mesmo. 


\subsubsection{Centrais de Atendimento ao Cidadão em outros Estados}

\subsubsection{O Poupa-Tempo em São Paulo}

O primeiro Posto do Poupatempo foi inaugurado em 1997, na Praça do Carmo, próximo à Praça da Sé, marco zero da cidade de São Paulo. Com a aprovação da sociedade ao Padrão de Atendimento do Poupatempo, o Programa começou a se expandir. Hoje, são vinte e nove postos fixos de atendimento: Sé, Luz, Santo Amaro, Itaquera, São Bernardo do Campo, Guarulhos, Campinas Centro, Campinas Shopping, São José dos Campos, Ribeirão Preto, Bauru, Osasco, Santos, São José do Rio Preto, Jundiaí, Taubaté, Piracicaba, Caraguatatuba, Araraquara, Cidade Ademar, Presidente Prudente, São Carlos, Tatuí, Rio Claro, Franca, Botucatu, Araçatuba, Marília e Mogi das Cruzes.

Com foco constante no cidadão, foram concebidas as Unidades Móveis, que levam os principais serviços do Poupatempo à população residente em bairros $\mathrm{e}$ municípios distantes dos Postos Fixos. São Unidades Itinerantes que ficam de 3 a 15 dias em cada roteiro, de acordo com a demanda.

\subsubsection{O Na Hora no Distrito Federal}

Instituído pelo Decreto oㅜ 22.125, de 11 de maio de 2001, o Na Hora reúne em um único local, representações de órgãos públicos federais e distritais, de forma articulada, para a prestação de serviços públicos aos cidadãos. O Na Hora tem como finalidade facilitar o acesso do cidadão aos serviços públicos, simplificar as obrigações de natureza burocrática, assim como ampliar os canais de comunicação entre o Estado e o Cidadão.

Objetivos do Na Hora é prestar atendimento de alto padrão de qualidade, eficiência e rapidez, ampliar o acesso do cidadão aos serviços públicos; Simplificar as obrigações de natureza burocrática; ampliar os canais de comunicação entre o Estado e o Cidadão. 
Os benefícios para o cidadão são: Atendimento com conforto e agilidade; aumento da eficiência na prestação dos serviços; economia de tempo e esforço; redução de custos; valorização do servidor público.

\subsubsection{O Vapt-Vupt na Bahia}

Vapt-Vupt - Serviço Integrado de Atendimento ao Cidadão foi criado através do Decreto № 5.177, de 29.02.2000, alterado pelo Decreto № 5.575, de 22.03.2002, com o objetivo de ampliar o acesso do cidadão às informações e aos serviços públicos de qualidade, visando proporcionar um atendimento diferenciado, rápido e eficaz, com qualidade, eficiência e produtividade. Com a grande aceitação que o Programa teve por parte da comunidade goiana, a rede de unidades fixas se expandiu de forma espetacular em quase 12 (doze) anos de atividades, contabilizando 22 (vinte e dois) postos fixos em funcionamento. Essa consolidação do Vapt-Vupt demanda ações que envolvem grande vulto de recursos, tanto físicos como humanos e financeiros. Para possibilitar melhor gestão desses recursos foi editada a Lei № 17.086, que disciplina o funcionamento do Vapt-Vupt.

Em 17 de outubro de 1999 foi inaugurada a primeira unidade fixa do VaptVupt, no Centro Comercial Buriti Shopping, no município de Aparecida de Goiânia.

Hoje em dia o Vapt-Vupt tornou-se o referencial que muitos Estados buscam, devido aos parâmetros de excelência alcançados pelo Programa.

\subsubsection{Atendimento integrado: o que se espera do governo}

Um processo integrado que sirva como central de atendimento visa atender às expectativas de melhor atendimento como:

- Oferecer ao cidadão condições para que possa interagir com apenas um funcionário para solicitar mais de um serviço, ainda que de diferentes esferas de governo.

- Permitir ao cidadão acompanhar o "status" de sua solicitação, quando for o caso. 
- Desobrigar o cidadão de providenciar determinadas exigências de informações (dados cadastrais, documentos, etc.), quando estas já fizerem parte de sistemas informatizados pertencentes ao Estado.

- Transformar o relacionamento pontual e fragmentado entre estado e cidadão em um relacionamento progressivo e cumulativo, consolidando-o de forma responsável e transparente.

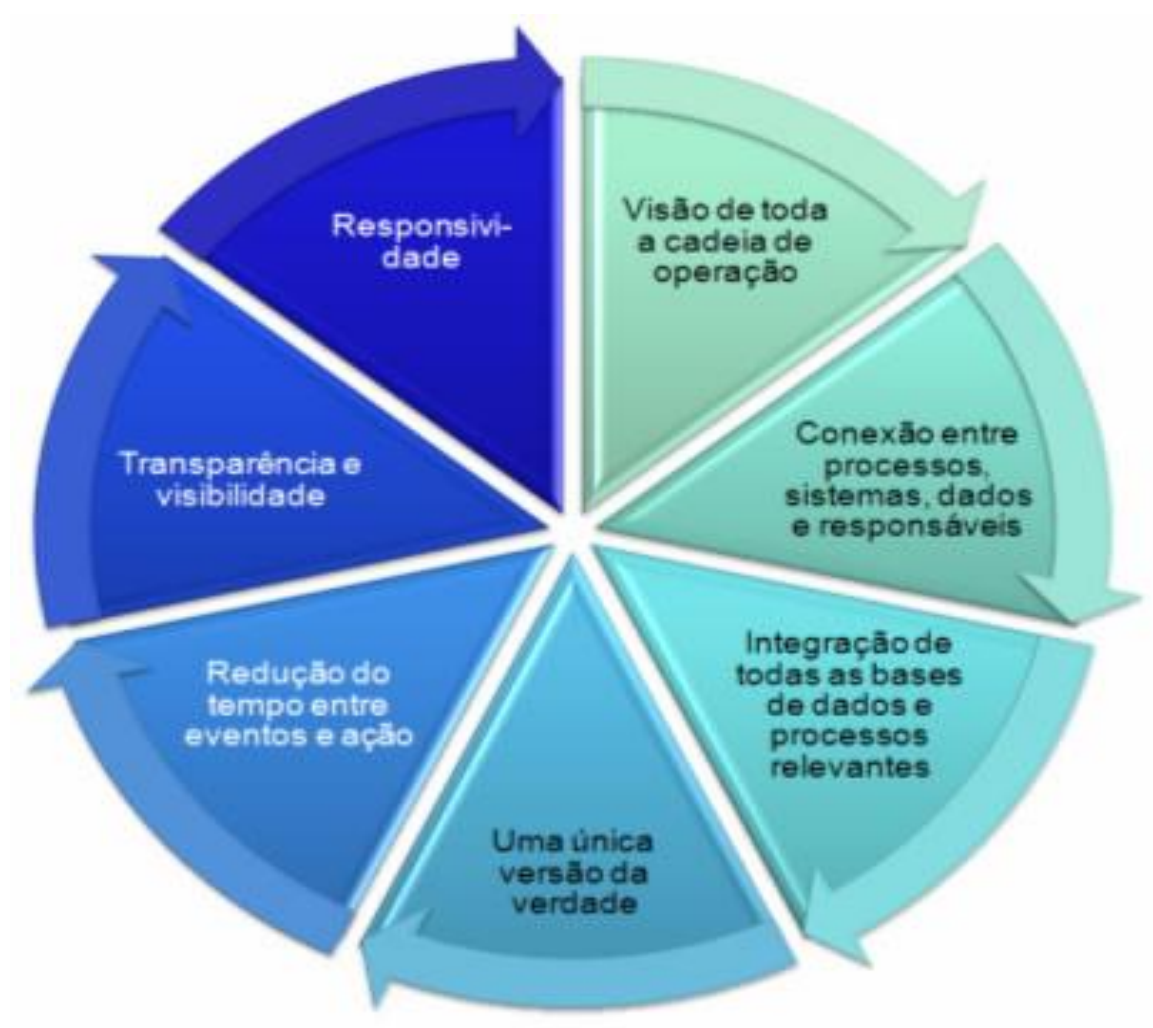

Figura 1: $O$ que se espera de um novo ambiente de suporte de informações para atendimento integrado aos cidadãos.

Integração de processos de governo - serviços ao cidadão

Fonte: http://igov.com.br/tigov/?p=116

Promover a universalização do acesso às informações e aos serviços por meio da disponibilização de diferentes e diversos canais de relacionamento e comunicação com a população: do presencial ao eletrônico. 


\subsubsection{Balcão Multisserviços na OCA}

O Balcão Multisserviços foi idealizado e implantado na OCA e se configura conceitualmente e na prática como posto de atendimento único, que permite a realização de vários serviços, prestados por diversas entidades, com uma só senha de atendimento. Esse conceito é o mesmo empregado em Portugal, nas "Lojas do Cidadão" e qualifica as Centrais de atendimento como Centrais de segunda geração. Pelo BM, resumidamente, o cidadão passa por um guichê, informa o que é necessário para realização dos serviços, senta-se uma única mesa e lá recebe todos os documentos que solicitou ou recebe protocolo de retirada, quando o documento não é emitido de forma imediata.

Uma arquitetura procedimental inovadora foi criada, denominada de Retaguarda. Seu papel é articular as informações colhidas do cidadão no BM e repassá-las aos órgãos provedores de serviços, criando uma teia de ações, onde cada órgão receba a informação de que necessita, a fim de que o cidadão receba o produto final: - seus documentos. Dessa forma, é imprescindível que a tríade - BM, Retaguarda e órgão prestador de serviço - estabeleçam uma articulação sincrônica que evidencie um fluxo específico de atendimento que corrija uma série de distorções e disfunções que caracterizaram a prestação de serviços públicos ao longo dos anos. (GOMES, 2011, p. 9) 
ATENDIMENTO NO BALCÃO MULTISSERVIÇOS

\begin{tabular}{|c|c|}
\hline \multicolumn{2}{|r|}{ PROCESSO DE ATENDIMENTO } \\
\hline PASSO & ATIVIDADE \\
\hline $1^{\circ}$ & Chamamento da senha pelo SIGA - Sistema de Gestão do Atendimento. \\
\hline $2^{\circ}$ & Saudação inicial ao cidadão. \\
\hline $3^{\circ}$ & $\begin{array}{l}\text { Solicitação da senha e da Comanda de Serviços para confirmar o seu } \\
\text { chamamento. }\end{array}$ \\
\hline $4^{\circ}$ & Início do atendimento no SIGA. Sistema de Gestão do Atendimento. \\
\hline $5^{\circ}$ & $\begin{array}{l}\text { Início do atendimento no Portal de Atendimento Multisserviços - PAM: } \\
\text { Triagem e Conferência dos pré-requisitos e documentos necessários na } \\
\text { Área de Trabalho BM. Vale ressaltar, que as perguntas-chave devem } \\
\text { ser devidamente dirigidas ao cidadão, conforme o uso da referida } \\
\text { ferramenta de atendimento. }\end{array}$ \\
\hline $6^{\circ}$ & Impressão das Listas de Dossiê (uma para cada órgão). \\
\hline $7^{\circ}$ & Preenchimento do Protocolo BM, manualmente. \\
\hline $8^{\circ}$ & $\begin{array}{l}\text { Montagem da senha BM no SIGA (verificação da existência de } \\
\text { interdependência entre os serviços). }\end{array}$ \\
\hline $9^{\circ}$ & $\begin{array}{l}\text { A Retaguarda: } \\
\text { a) fotocopia e autentica o(s) documento(s) do cidadão; } \\
\text { b) recolhe as Listas de Dossiê impressas; } \\
\text { c) monta um dossiê para cada órgão, contendo: a Lista de Dossiê e a } \\
\text { cópia do(s) documento(s) do cidadão, conforme a necessidade dos } \\
\text { serviços. } \\
\text { d) encaminha os Dossiês aos órgãos que prestam os serviços } \\
\text { pretendidos. }\end{array}$ \\
\hline $10^{\circ}$ & $\begin{array}{l}\text { O Atendente BM: } \\
\text { a) explica sobre o chamamento da senha (senha - monitor - mesa - } \\
\text { direção dos órgãos); } \\
\text { b) entrega a senha, a Comanda de Serviços e o Protocolo BM ao } \\
\text { cidadão e esclarece que estes deverão ser apresentados em todos os } \\
\text { órgãos aos quais for chamado. }\end{array}$ \\
\hline $11^{\circ}$ & $\begin{array}{l}\text { Saudação final ao cidadão e direcionamento à Área de Espera da Praça } \\
\text { Verde. }\end{array}$ \\
\hline $12^{\circ}$ & Finalização do Atendimento no SIGA. \\
\hline
\end{tabular}

Observação: Nos $8^{\circ}$ e $9^{\circ}$ Passos, o Atendente BM e a Retaguarda trabalham simultaneamente.

Figura 2 e 3 : A figura representa o fluxo do Balcão Multisserviços - processos de atendimento Disponível: Balcão Multisserviços e Nova Política de Atendimento ao Cidadão são destaques no IV CONSAD. Disponível em: $<$ http://ocaacre.blogspot.com/2011/05/balcao-multisservicos-e-nova-politica.html> Acesso em: 24 set. 2011. 
ATENDIMENTO NOS ÓRGÃOS ESPECIALIZADOS

\begin{tabular}{|c|c|}
\hline \multicolumn{2}{|r|}{ PROCESSO DE ATENDIMENTO } \\
\hline PASSO & ATIVIDADE \\
\hline $1^{\circ}$ & $\begin{array}{l}\text { Recebimento da Pasta BM por parte do Supervisor do Órgão } \\
\text { Especializado. }\end{array}$ \\
\hline $2^{\circ}$ & Chamamento da senha pelo sistema SIGA. \\
\hline $3^{\circ}$ & $\begin{array}{l}\text { O Supervisor do Órgão entrega a Pasta BM para o Atendente } \\
\text { Especializado. }\end{array}$ \\
\hline $4^{\circ}$ & Saudação inicial ao cidadão. \\
\hline $5^{\circ}$ & $\begin{array}{l}\text { Solicitação da senha, do Protocolo BM e da Comanda de Serviços do } \\
\text { cidadão para confirmar o seu chamamento. }\end{array}$ \\
\hline $6^{\circ}$ & Início do atendimento no SIGA. \\
\hline $7^{\circ}$ & $\begin{array}{l}\text { O Atendente Especializado utiliza o Protocolo BM, a Lista de Dossiê e a } \\
\text { fotocópia do(s) documento(s) do cidadão, a fim de: } \\
\text { a) identificar qual é o serviço solicitado pelo cidadão; } \\
\text { b) Obter os dados pessoais e documentais do solicitante (nome, data de } \\
\text { nascimento, filiação, endereço, telefone etc). } \\
\text { c) ter ciência se aquele atendimento é o último a ser executado; }\end{array}$ \\
\hline $8^{\circ}$ & $\begin{array}{l}\text { No ato de conclusão do atendimento, o Atendente Especializado deve: } \\
\text { a) dar todas as orientações necessárias ao cidadão sobre o serviço em } \\
\text { conclusão; } \\
\text { b) caso o cidadão tenha que esperar um próximo atendimento, orientá- } \\
\text { lo sobre o chamamento da senha; } \\
\text { c) preencher o Protocolo BM no campo "Status do Atendimento" } \\
\text { informando se o serviço ficou PENDENTE ou CONCLUíDO e deixar } \\
\text { assinalado; } \\
\text { d) reter a Pasta BM no órgão e devolver a cópia do documento ao } \\
\text { cidadão (exceto quando a cópia precisa ficar retida, como ocorre nos } \\
\text { serviços de Carteira de Identidade, por exemplo). } \\
\text { Observação: Se o serviço ficou PENDENTE, o atendente especializado } \\
\text { deve explicar ao cidadão o motivo da não conclusão. Em seguida, } \\
\text { verificar se há interdependência entre o serviço e o(s) próximo(s) } \\
\text { serviço(s) solicitados. Se houver, o cidadão deve ser informado que } \\
\text { haverá impedimento para solicitar a confeç̧ão do(s) outro(s) } \\
\text { documento(s) em virtude da interdependência. Compete ao Supervisor } \\
\text { do Órgão o cancelamento da senha e a entrega da Pasta ao BM. }\end{array}$ \\
\hline $9^{\circ}$ & Saudação final ao cidadão. \\
\hline $10^{\circ}$ & Finalização do Atendimento no SIGA. \\
\hline
\end{tabular}

Figura 3: O Fluxo do Balcão Multisserviços, processos de atendimento especializado.. 


\section{MÉTODOS E TÉCNICAS DE PESQUISA}

Foi realizado um estudo de caso da Organização das Centrais de Atendimento com objetivos de conhecer, analisar e qualificar a política de atendimento ao cidadão no Acre e o modelo adotado de atendimento em centros integrados.

Considerando Matias-Pereira (2007, p. 44), para quem, "Pesquisar é um esforço desenvolvido pelo investigado para coletas informações e dados essenciais a fim de responder a uma pergunta motivadora e dessa forma alcançar os objetivos da pesquisa", o objetivo desta seção é apresentar os aspectos metodológicos empregados na presente pesquisa para atingir seus fins.

\subsection{Caracterização da organização, setor ou área}

A Organização em Centros de Atendimento - OCA é uma central de serviço público existente na cidade de Rio Branco/AC que reúne 26 órgãos, das esferas municipal, estadual e federal, para a prestação em um único espaço físico de mais de 500 serviços. Está localizada na esquina da Avenida Brasil com a Rua Quintino Bocaiúva, no centro da capital, funcionando de segunda a sexta-feira, das 08:00h às 18:00 horas; possui, ainda, uma unidade no município de Xapuri/AC.

Sua criação é decorrência da implantação da Política de Atendimento ao Cidadão instituído pelo Decreto Estadual № 3.357, de 20 de agosto de 2008, por meio da qual se estabeleceu que os serviços públicos devessem ser prestados com a máxima atenção, cortesia e eficiência ao cidadão, razão pela qual a convergência dos atendimentos facilita o acesso por parte de usuários.

A estrutura física e logística é inovadora e uma das mais modernas do país, e o atendimento são prestados sem discriminação e/ou privilégios não estabelecidos na legislação e com alto padrão de excelência.

Para facilitar o pagamento de boletos, taxas, tributos e tarifas diversas, a Organização possui dois postos bancários (Banco do Brasil, Caixa Econômica) e 
conta com guia de usuários para o fornecimento completo de informações, serviços de Internet e autoatendimento.

Os órgãos e entidades que prestam atendimentos na OCA são: Acreprevidência, Instituto de Identificação da Secretaria de Polícia Civil do Estado do Acre, Tribunal Regional Eleitoral do Estado do Acre, Cartórios do Tribunal de Justiça do Estado do Acre, Secretaria de Estado de Saúde do Acre, Sistema Nacional de Empregos da Secretaria de Estado de Desenvolvimento, Ciência e Tecnologia, Empresa Brasileira de Correios e Telégrafos, Departamento de Polícia Federal, Sindicato das Empresas de Transporte Coletivo do Estado do Acre, Secretaria de Estado de Gestão Administrativa do Acre, Companhia de Habitação do Estado do Acre da Secretaria Estadual de Habitação e Interesse Social, Defensoria Pública do Estado do Acre, Divisão de Credenciamento Escolar da Secretaria de Estado de Educação, Eletrobrás - Distribuição Acre, Departamento Estadual de Proteção e Defesa do Consumidor, Secretaria de Estado de Desenvolvimento para Segurança Social, Instituto de Administração Penitenciária, Sistema Fácil, Secretaria de Estado da Fazenda, Corpo de Bombeiros Militar do Acre, Conselho Regional de Contabilidade do Estado do Acre, Prefeitura Municipal de Rio Branco e Departamento Estadual de Trânsito.

\subsection{Participantes do estudo}

Os participantes do estudo foram os gerentes da OCA, pois são os responsáveis pela implementação nova política de atendimento ao cidadão no Acre e os mesmo tem o conhecimento de como se deu essa implementação quais os entraves e as dificuldades enfrentada.

A diretoria da Oca, pois direciona todas as demandas provenientes do atendimento e está diretamente responsável pela qualidade e implementação do Decreto lei que institui o novo modelo de atendimento ao cidadão no Acre.

Os pesquisadores que de algum modo estudaram e conheceram os problemas e dificuldades enfrentadas e os desafios do novo modelo de atendimento 
no Acre estiveram em campo para quantificar o nível de satisfação dos cidadãos usuário, através de questionário.

Os funcionários que lidam todos os dias com o público da Oca e estão diretamente ligados ao sucesso da implementação dessa política.

Com a visão desses profissionais é possível qualificar esse estudo como também descrever sobre seus principais desafios e dificuldades encontrada nesse novo modelo de atendimento integrado, que visa o cidadão como participantes do processo e fiscalizador dos serviços, detentor do controle social.

\subsection{Caracterização dos instrumentos de pesquisa}

$\mathrm{Na}$ caracterização dos instrumentos de pesquisa deste trabalho, utilizou-se a classificação de Vergara (2007), que o faz quanto aos meios e quanto aos fins.

Assim, quanto aos fins, este trabalho é considerado exploratório e descritivo, pois busca explorar uma realidade, ainda pouco conhecida em sua fase inicial, para então descrevê-la, expondo as características claras e bem delineadas de seu objeto.

Doutra ponta, quanto aos meios, a pesquisa é considerada, primeiramente, bibliográfica, por ter sido realizado um levantamento prévio da literatura disponível, e depois, de campo/estudo de caso, pois que se buscou entender a realidade de uma instituição em funcionamento, balizando-se na experiência que se está sendo vivida na investigação, exatamente na própria instituição onde são observados os fenômenos estudados. Dessa forma foi efetuada uma entrevista estruturada com o gerente e a Diretora da OCA e depois foi feita uma comparação com os dados coletados através da investigação e observação e descrição dos fenômenos colhidos. 


\subsection{Procedimentos de coleta e de análise de dados}

Foi utilizado como instrumento de coleta, primeiramente entrevistas estruturada e abertas, baseada no roteiro do programa de administração pública voltada ao cidadão (Anexo 4- Quadro-síntese - Manual de gestão pública contemporânea.

.Dessa forma foram feiras uma (1) entrevistado estruturado com o gerente administrativo geral e uma (1) entrevista com o pesquisador dos dados recentes coletados na OCA sobre a satisfação do atendimento em vários aspecto estudado.

Por outro lado, também foram utilizados técnica de observação, através de visitas e busca pelo atendimento a fim de identificar e vivenciar alguns processos que $o$ cidadão passa durante $o$ atendimento.

.Dentre outras, a pesquisa em revistas cientificas disponibilizada em sites, decreto, leis artigos cientifico que versam sobre a política de atendimento ao cidadão no Acre, foram de fundamental importância para conhecimento prévio do assunto abordado.

Esse trabalho perdurou por, aproximadamente, seis meses, sendo que foram rezados alguns testes pelo autor, uma vez que buscou atendimento em algumas demandas pessoais, como: segunda via de carteira de identidade, certidão de antecedentes criminais e serviços de validação de histórico escolar com o objetivo de entender os procedimentos e como se dá o atendimento ao cidadão que precisa diariamente desses serviços de forma eficiente.

Em diversos momentos foram realizadas visitas institucional com a própria diretora acompanhando e fornecendo alguns dados da OCA.

Além disso, foram realizadas algumas participações em treinamento na instituição que corresponde à capacitação do servidor público para as melhoria e qualificação do atendimento ao cidadão, a fim de proporcionar qualidade no atendimento e melhoria continua. Essa capacitação é feita por uma pessoa qualificada que buscar formar pessoas que saiam da condição de burocrata para um servidor gerencial e consciente de que o cidadão usuário é o cliente e precisa ser satisfeito 
Os dados foram analisados, predominantemente, pelo método qualitativo, bancando-se compreender o conteúdo e o discurso dos entrevistados à luz do referencial bibliográfico previamente levantado. 


\section{RESULTADOS E DISCUSSÃO}

Pode-se observar que a política de atendimento ao cidadão no Acre deu um salto em inovação e integração de serviços Públicos, muito embora em outros estados a política de atendimento já havia sido implementada há alguns anos, ainda é muito dificultoso o processo de evolução e progresso em alguns Estado do Brasil, no Acre não poderia ser diferente, pois somos um Estado jovem que tem apenas 100 anos de existência.

A forma com que se deu a implantação dessa nova política de atendimento ao cidadão foi bastante inovadora e eficaz, pois surge de um decreto que a instituiu. Segundo a Diretora da Oca, "O Acre é o primeiro Estado a ter uma política de atendimento voltada para o cidadão, através de um decreto, institucionalizada para todas as áreas de atendimento do Acre. A OCA é na verdade uma vitrine desse atendimento, pois reúne todas as condições para que este atendimento seja colocado em prática."

Hoje o cidadão já não precisa se deslocar por diversos setores em busca de atendimento da esfera estadual, federal e municipal, pois estes serviços, estão sendo oferecidos de forma integrada em um único lugar, organizada em Centos de Atendimento.

A participação do cidadão no controle social como o agente de mudança e o principal mediador entre o Estado e o governo não tem sido plena, uma vez que o cidadão nem sempre é consultado. Fora feito a seguinte pergunta em relação a esse controle: A OCA já experimentou segmentar a base de cidadãos-usuários em grupos para identificar suas expectativas quanto a tempo e modelos de atendimento? Um caso hipotético seria um atendimento especializado a cidadãos vindo de lugares longínquos ou em situação de extrema vulnerabilidade, "sem parente nem aderente".

Resposta: Não há esta segmentação no atendimento. O que temos e podemos analisar são realidades diferentes em alguns casos, como por exemplo, a realidade dos cidadãos atendidos na OCA Xapuri e na OCA Rio Branco. 
Ainda são perceptíveis algumas falhas quanto às organizações que tratam de ofertar os serviços ao cidadão diariamente. Percebe-se que falta muito ainda para que o Estado venha desempenhar o novo papel ao qual vem sendo questionado, o cidadão como cliente deveria ser consultado diante de muitas decisões.

Observou-se que a ambiência muita das vezes não é pensada, não é testada, ou não é simulada-validada, para se saber se está apropriada para quem ficará pelo menos meia hora a espera de seu atendimento, Mesmo que seja por poucos minutos, os ambientes devem estar preparados para acolher de forma satisfatória e agradável o cidadão, e não apenas na beleza estética, mas sim adequado para seu público e quanto à sua função. Observou-se que as cadeiras são de aço inox fria e deslizante, dessa forma produz um desconforto,

Percebeu-se que há uma formação de uma cultura organizacional voltada para atender com excelência o cidadão que hoje busca o atendimento, porém, ainda há muitas dificuldades em repassar a informação de forma clara e sucinta.

Muitos atendentes ainda deixam a desejar ou por falta de perfil ou por falta de qualificação, pois não é possível treinar todos ao mesmo tempo e essa capacitação sempre é feita por parte. Há uma escassez de recurso financeiro para gerenciamento e gasto com a formação e a capacitação de pessoal, um problema que poderá acarreta diminuição e comprometimento do atendimento e satisfação do cidadão quando ao atendimento integrado.

As formas com que a OCA proporciona os canais de acesso às informações são: presencial, eletrônica ou telefone, e há disponibilidade de Portfólio dos serviços ofertados cumprindo uma das exigências e indicação da carta de serviço ao cidadão direcionado as centrais. Perguntou-se se os cidadãos têm liberdade de escolha no que concerne às opções dos canais de acesso aos serviços oferecidos pela OCA? Exemplifique.

Sim, o cidadão pode escolher como ter as informações sobre os serviços, para isso utilizar da forma presencial, eletrônica ou telefone.

Outro fundamento é a informação. O cidadão tem o canal de manifestações para expressar a sua satisfação, sugestão ou reclamação, não só sobre novos serviços, mas também sobre todos os assuntos relacionados à qualidade no atendimento, isso se dá através da escrita e telefônica, onde os usuários podem 
escrever e depositar nas caixinhas de sugestão, a OCA tem uma estimativa de resposta em até 24 e 72 horas.

Procurou saber se a OCA busca medir a satisfação e percepções dos cidadãos, promovendo feedbacks por meio de uma maior variedade de instrumentos de consulta? Existe alguém formalmente responsável e treinado em metodologia de pesquisa para avaliar os dados coletados e para dar respostas adequadas?

Foi respondido que: sim, a OCA tem um canal de manifestações que se apresenta com as seguintes variantes: manifestação escrita, manifestação eletrônica e ouvidoria. Existe a Coordenação de atendimento que está totalmente capacitada para esta função. A OCA faz um atendimento circunstanciado a pessoas incapacitadas de buscar os serviços nas instalações da Central. Para tanto é disponibilizado uma equipe móvel que se desloca até o local onde o cidadão se encontra, por exemplo: hospital, residência, presídio paro a confecção de alguns serviços. Mas como já foi falado, é perceptível que essa satisfação só é medida se o cliente buscar e não há uma preocupação em medir cada atendimento individualizado a menos que ele queria deixar uma sugestão ou reclamação.

Fora perguntado sobre se há uma preocupação com a divulgação das inovações planejadas ou realizadas, que esclareça exaustivamente os cidadãos sobre como podem utilizar o novo serviço e contribuir para o seu aperfeiçoamento? Que ferramentas ou metodologias são utilizadas?

A resposta dada foi: Outro fundamento base de nosso projeto é a informação, o cidadão tem o canal de manifestações para expressar a sua satisfação, sugestão ou reclamação, não só sobre novos serviços, mas também sobre todos os assuntos relacionados à qualidade no atendimento

Uma das experiências vivenciadas na fase de coleta para a presente pesquisa - uma reclamação real deixada na caixinha de sugestões, propositalmente - foi respondida me menos de 20 horas, prazo menor que o estimado pela instituição (24h). A reclamação versava sobre o repasse de informações fragmentadas, ou seja, incompletas, ocasionando, assim, maior demora para o autor (cidadão), uma vez que teve que enfrentar filas diversas, cada uma por vez, o que poderia ter sido mais ágil, pois o autor (cidadão) estava acompanhado por outro cliente na mesma demanda. 
Tal dilema demonstra claramente que a burocracia (disfuncional) ainda está presente na administração hodierna, pois, conforme política da própria instituição o cidadão deve ser atendido de forma integral em suas necessidades, enfrentando uma única fila.

\subsection{Gráfico 1: Atendimentos Efetivados Diariamente na OCA}

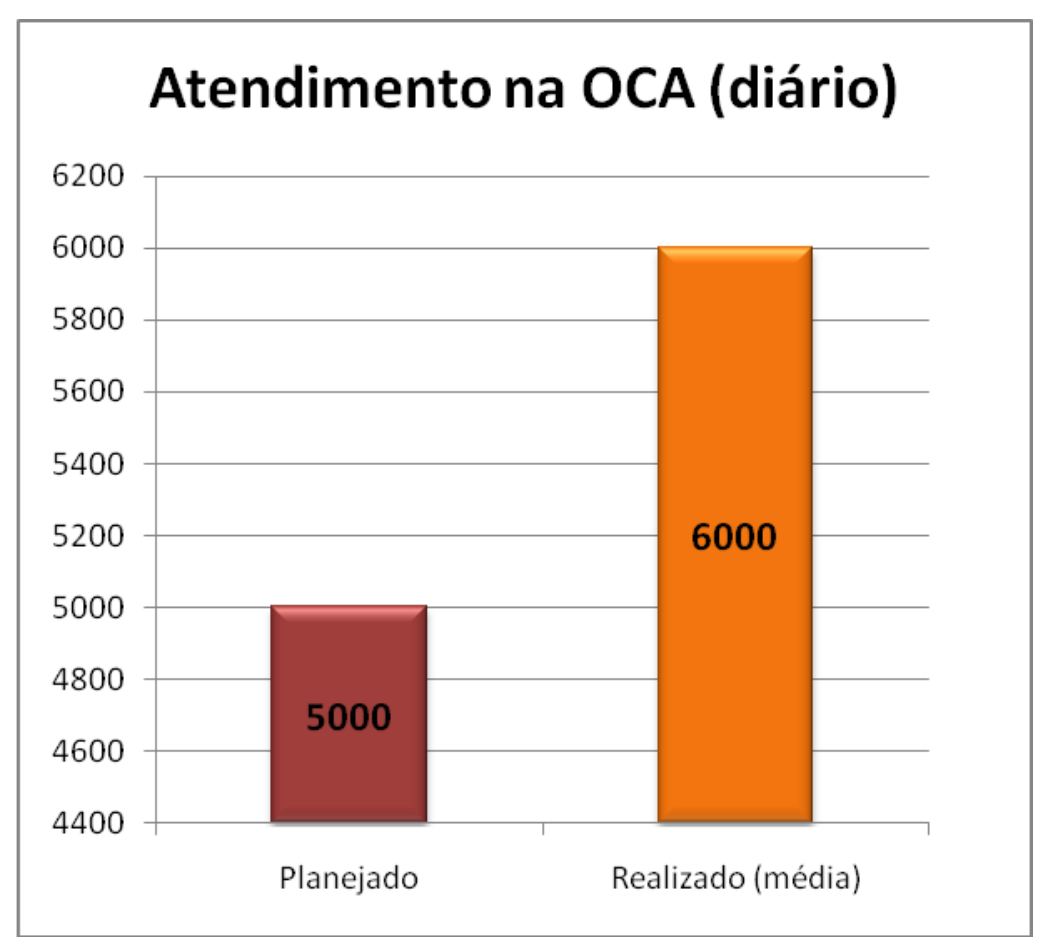

Fonte: Dados primários coletado da diretoria da OCA

A OCA foi planejada para realizar em média 5.000 mil atendimentos diarios, no entanto superou as expequitativa do governo e hoje atende em torno de 6000 diários chegando até 8.000 em dias de pico. Percebe-se que a população realmente está buscando o atendimento integrado. Visto que hoje as facilidades ofertadas pela OCA tornam os serviços prestados ágeis e eficientes. 


\subsection{Gráfico 2: Distribuição dos funcionários da OCA}

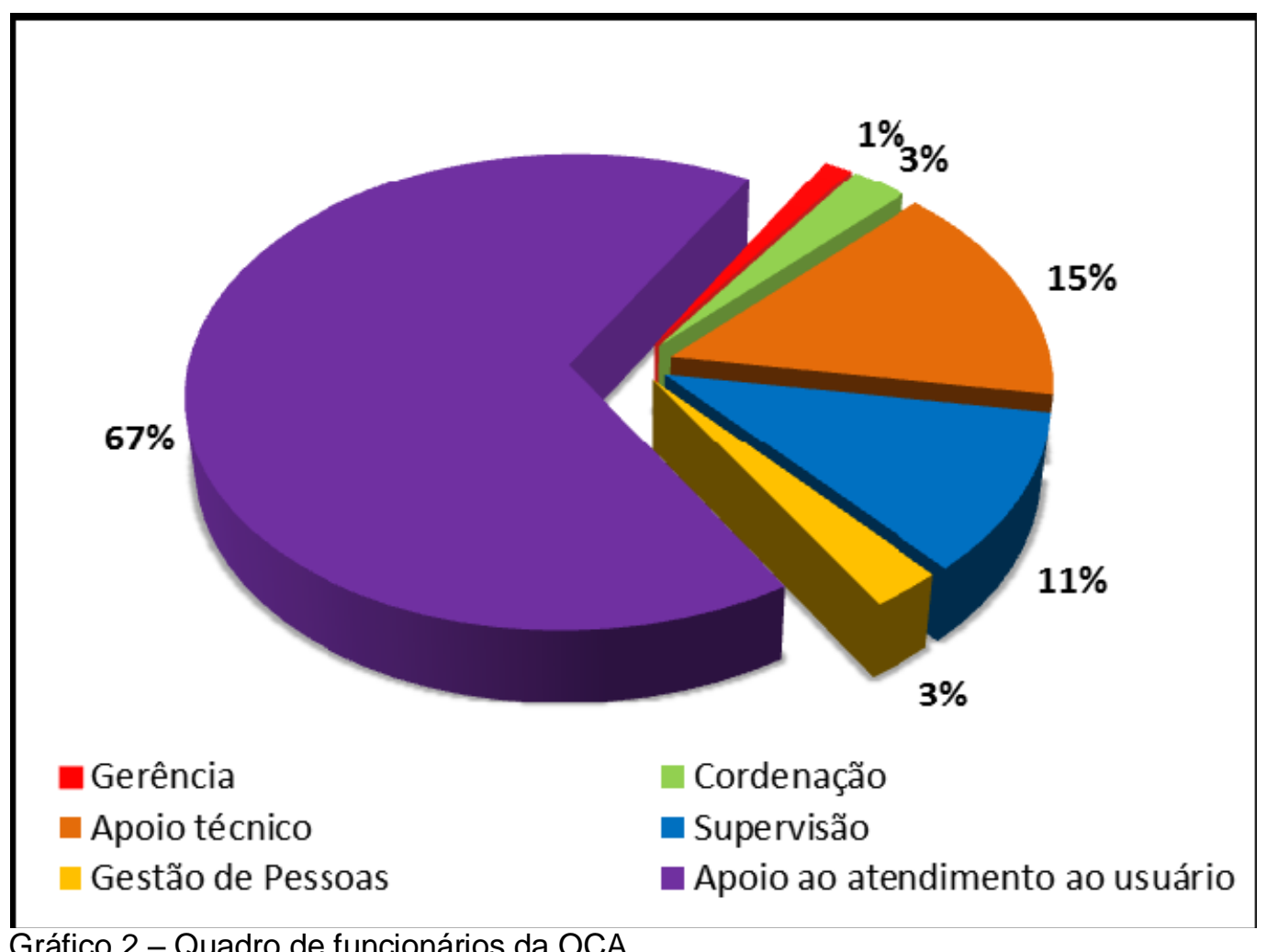

Gráfico 2 - Quadro de funcionários da OCA

Fonte: NOGUEIRA, Henry Antônio Silva, abril. 2011. A Eficiência na Prestação do Serviço Público: Um Estudo de Caso nas Organizações em Centros de Atendimento (OCA) Acre. Disponível em: <http://www.tce.ac.gov.br/xoops/uploads/c0a80b0b-e6f6-7690.pdf>. Acesso em: 20 nov. 2011.

Verifica-se no gráfico 2, que $67 \%$ dos servidores lotados na administração da OCA, trabalham no atendimento e apoio do usuário dos serviços oferecidos. Esse fato é bastante relevante, pois agiliza os processo de atendimento, e contribuir para um melhor desempenho do atendente. Os demais 33\% dos funcionários estão distribuídos nas outras atividades da administração, e diretamente nos procedimentos referentes a análises, gestão dos sistemas, supervisão, coordenação, gestão de pessoas, apoio técnico e gerência. 


\section{CONSIDERAÇÕES FINAIS E RECOMENDAÇÕES}

Finalmente, podemos concluir que a Política de atendimento desenvolvida pela OCA vem contribuindo para melhorar o relacionamento entre o Estado e a sociedade, isso porque tem buscado alinhar-se a um novo padrão desenhado para o aparelhamento do estado e seus serviços.

A estrutura física e logística é inovadora e uma das mais modernas do país. O atendimento é prestado sem discriminação e/ou privilégios não estabelecidos na legislação e com alto padrão de excelência, pela qual a convergência dos atendimentos facilita o acesso por parte de usuários. Dessa forma, é possível perceber que embora haja alguns entraves que dificultam as mudanças decorrentes do Estado burocrático para o modelo gerencial, percebe-se que essas questões são toleráveis pelo fato de estarem entranhados por todos os setores, sendo a herança de nosso histórico patrimonialista e burocrático.

É preciso romper com esses paradigmas para construir uma nova cultura onde os servidores públicos são remodelados com um novo padrão de comportamento em todos os níveis de atuação na prestação de serviços à sociedade.

Nesse novo contexto é preciso resgatar a dignidade dos agentes públicos. $O$ servidor necessita enxergar-se como parte dos processos e ser um agente ativo, participativo e principal agente de mudança, reduzindo as barreiras entre o Estado e o cidadão.

Os efeitos positivos das Organizações em Centros de Atendimento são visíveis e ansiados pelos demais municípios do estado do Acre. Por isso, não apenas por ser a capital Rio Branco um município referência em atendimento, mas, pelo fato de os usuários dos serviços públicos precisarem do acesso e esses benefícios, a exemplo de Xapuri, outros municípios do Estado também precisam ser contemplados com uma possível expansão desse atendimento integrado.

Orientando-se pela qualidade e celeridade dos serviços prestados e pelas mudanças já provocadas, que impactaram positivamente a imagem e avaliação da competência do serviço público no Acre, a pretensa expansão para os demais 
municípios deveria ser considerada pelo Governo, num futuro não distante. Pois, assim, fortalecem-se os valores democráticos, a transparência e o necessário controle social do cidadão. 


\section{REFERÊNCIAS}

ACRE. Central de Serviço Público de Rio Branco. Disponível em:

$<$ http://www.gsp.acre.gov.br/index.php?option=com_content\&task=view\&id=51\&ltemi $\mathrm{d}=1937$. . Acesso em: 9 jun. 2011.

Decreto Estadual no 3.357, de 20 de agosto de 2008. Institui a Política de Atendimento ao Cidadão para a Administração Pública Estadual e constitui instâncias responsáveis pela sua implementação e acompanhamento. Disponível em:

$<$ http://www.gsp.acre.gov.br/index.php?option=com_content\&task=view\&id=51\&ltemi $\mathrm{d}=1937$. . Acesso em: 10 set. 2011.

Floresta Digital. Disponível em: < http://www.florestadigital.acre.gov.br/\#>. Acesso em: 10 out. 2011.

Balcão Multisserviços e Nova Política de Atendimento ao Cidadão são destaques no IV CONSAD. Disponível em: <http://oca-acre.blogspot.com/2011/05/balcaomultisservicos-e-nova-politica.html> Acesso em: 24 jun. 2011.

BRASIL, Constituição (1988). Constituição da Republica Federativa do Brasil. Brasília. DF: Senado, 1988.

. Ministério do Planejamento, Orçamento e Gestão. Secretaria de Gestão. Programa Nacional de Gestão Pública e Desburocratização - Gespública; Prêmio Nacional da Gestão Pública - PQGF; Carta de Serviços ao Cidadão; Brasília; MPOG, Seges, 2009. Versão 1/2009.

BRESSER-PEREIRA, Luiz Carlos. (1998), Reforma do Estado para a Cidadania: A Reforma Gerencial Brasileira na Perspectiva Internacional. Brasília: ENAP; São Paulo: Editora. 34. 365 p.

BRESSER, Pereira e outros. Plano Diretor da Reforma do Estado. Disponível em:<http://www.bresserpereira.org.br/Documents/MARE/PlanoDiretor/planodiretor.p df>. Acesso em 26 jun. 2011.

CANZONIERI, Ana Maria. Metodologia da Pesquisa Qualitativa na Saúde. Petrópolis, RJ. Vozes. 2010.

COSTIN, Claudia, Administração Pública 1 ed. Rio de Janeiro: Elsevier, 2010

COUTINHO, M. J. V. (2000), "Administração pública voltada para o cidadão: quadro teórico- RSP conceitual". Revista do Serviço Público, Brasília, ano 51, n. 3, jul-set. DF. Central de Atendimento ao Cidadão "Na Hora". <http://www.nahora.df.gov.br/> Acesso em: 18 set. 2011.

GOIAS. Central de Atendimento ao Cidadão "Vapt-Vupt". Disponível em: <http://www.vvv.goias.gov.br/post/ver/104086/vapt-vupt> Acesso em: 18 set. 2011. 
GOMES, Sídia Maria Cordeiro, Balcão Multisserviços Viabilidade de Integração entre Órgão .IV Congresso CONSAD de Gestão Pública. 25 a 27 de maio de 2011. Painel 36/129. Disponível em: <http://www.consad.org.br/consad/acontece.aspx>. Acesso em: 24 nov. 2011

Instituto de Governo Eletrônico. O que se espera de um novo ambiente de suporte de informações para atendimento integrado aos cidadãos Disponível em: <http://igov.com.br/tigov/?p=116>. Acesso em: 24 out. 2011.

MARTINS, Gilberto de Andrade; LINTZ, Alexandre. Guia para Elaboração de Monografias e Trabalhos de Conclusão de Curso. 2 ed. São Paulo: Atlas, 2010.

MATIAS-PEREIRA, José. Administração pública comparada: uma avaliação das reformas administrativas do Brasil, EUA e União Européia. Rev. Adm. Pública, vol.41, ํo. 1. Rio de Janeiro, jan./fev. 2008.

. Curso de Administração Pública: Foco as instituições e Ações Governamentais. São Paulo, Atlas, 2010.

Manual de gestão pública contemporânea. São Paulo Atlas, 2009. 2007.

Metodologia Científica: Manual de Pesquisa Científica. Brasília. FACE/UnB.

NEVES, Graziela Maria Fernandes. Política de Atendimento Ao Cidadão Requisito Para Elevar O Padrão E A Qualidade Dos Serviços Prestados Pelo Setor Público. IV Congresso CONSAD de Gestão Pública. 25 a 27 de maio de 2011. Painel 42/149. Disponível em: <http://asseppgg.com.br/index.php?option=com_phocadownload\&view=category\&do wnload=35:texto\&id=2: documentos\&ltemid=75> . Acesso em 27 jun. 2011.

NOGUEIRA, Henry Antônio Silva, abril. 2011. A Eficiência na Prestação do Serviço Público: Um Estudo de Caso nas Organizações em Centros de Atendimento (OCA) Acre. Disponível em: <http://www.tce.ac.gov.br/xoops/uploads/c0a80b0b-e6f6-7690.pdf>. Acesso em: 20 nov 2011

PALASSI, Márcia Prezotti; BRANDIÃO, Hugo Junior; FERREIRA, Dirce Nazaré Andrade "Administração Publica"- UAB. 2007.

SÃO PAULO. Central de Atendimento ao Cidadão "Poupa-Tempo". Disponível: <http://www.poupatempo.sp.gov.br/oqueeopoupa/index.asp>. Acesso em: 18 set 2011. 


\section{APÊNDICES}

\section{PROJETO DE PESQUISA/ROTEIRO DA ENTREVISTA}

POLÍTICA DE ATENDIMENTO AO CIDADÃO: Um estudo de caso da OCA Organização das Centrais de Atendimento

Aluno: Alyssandra Correa de Morais dos Santos

Professor Orientador: Esp. Josias Rodrigues Alves

Professor Supervisor: Dr. José Matias-Pereira

OBETIVO GERAL: Conhecer, analisar e avaliar a efetividade da Política de atendimento ao cidadão, no município de rio Branco com vistas à sua expansão para os demais municípios.

\section{Objetivo da Entrevista:}

Entrevista abertas com gerente da organização - OCA, com vista à mensuração do grau de efetividade da Política de Atendimento ao Cidadão, com o foco no cidadãocliente.

1- Há incentivo por parte da Gestão do Órgão na formação de uma cultura administrativa de atendimento centrada no cidadão. Como?

Sim, há total incentivo de atendermos com qualidade o cidadão, sendo que para isso temos todo o suporte para trazermos inovações para este processo.

2- Os cidadãos têm liberdade de escolha no que concerne a opções dos canais de acesso aos serviços oferecidos? Como?

Sim, o cidadão pode escolher como ter as informações sobre o serviços, para isso utilizar da forma presencial, eletrônica ou telefone.

3- A instituição buscar apoio e sustentação política de outras Secretarias? De que forma?

A OCA tem como "norte" a política de atendimento ao cidadão, que também deve ser balizadora para todos os órgãos estaduais. Outra forma de buscar apoio e sustentação é trabalhar com o modelo de gestão participativa, onde todos os envolvidos contribuem para a melhoria do projeto.

4- A instituição dispõe de lideranças, formais ou informais, nos níveis administrativos e de atendimento, inclusive nas altas gerências dentro das organizações.

Sim, trabalhamos com o modelo de gestão participativa, onde há total incentivo para formação de lideranças de equipes, sempre buscando o aprimoramento do trabalho.

5- A instituição tem algum novo programa de serviço, em andamento ou em planejamento, para curto, médio e longo prazo, ou mesmo algum projeto piloto para experiência e eventuais ajustes. Qual (is)? 
Alguns, posso citar, o Balcão Multisserviços que está constantemente sendo ajustado e aprimorado.

6- A instituição consulta os stakeholders, isto é, indivíduos ou grupos que tenham interesse no desempenho do sistema ou da organização? Quais e como?

Não tenho conhecimento de algum trabalho neste sentido.

7- A instituição investe no treinamento de pessoal e no capital tecnológico e logístico? Como? Há algum exemplo recente?

Sempre. Como premissa para início dos trabalhos, todos os atendentes participaram de 3 meses de capacitação e há um processo intermitente de capacitação continuada. Quanto aos recursos tecnológicos e logísticos, foi feito um grandioso investimento para alinhar capacidade humana à capacidade tecnológica, hoje trabalhamos com uma excelente infraestrutura tecnológica e logística.

8- A instituição cria parcerias baseadas na unificação de objetivos, igualdade de influência sobre as decisões, divisão equânime do reconhecimento pelo trabalho desenvolvido e nivelamento das políticas de recursos humanos?

Como já falado em questões anteriores, a gestão participativa é um dos pilares para que isto ocorra.

9- Há compartilhamento de informações sobre requerimentos tecnológicos e equipamentos de comunicação entre parceiros?

Podemos citar o fato de estarmos em um mesmo prédio com mais de 30 instituições, utilizando em comum infraestrutura lógica e de telecomunicações.

10-Há uma preocupação com a divulgação e explicação das inovações planejadas, esclarecendo exaustivamente como os cidadãos podem utilizar o novo serviço e contribuir para o seu aperfeiçoamento?

Outro fundamento base de nosso projeto é a informação, o cidadão tem o canal de manifestações para expressar a sua satisfação, sugestão ou reclamação, não só sobre novos serviços, mas também sobre todos os assuntos relacionados à qualidade no atendimento

11-A instituição já experimentou segmentar a base de cidadãos-usuários em grupos para identificar suas expectativas quanto a tempo e modelos de atendimento? Um caso hipotético seria um atendimento especializado a cidadãos vindo de lugares longínquos ou em situação de extrema vulnerabilidade, "sem parente nem aderente".

Não há esta segmentação no atendimento. O que temos e podemos analisar são realidades diferentes em alguns casos, como, por exemplo, a realidade dos cidadãos atendidos na OCA Xapuri e na OCA Rio Branco.

12-A instituição já se preocupou em estabelecer padrões de qualidade no atendimento combinando as expectativas dos cidadãos e a comparação com a eficiência e eficácia de outros serviços já oferecidos?

A OCA se configura como um novo padrão de atendimento, sendo que a partir da implantação desse novo modelo, a OCA que passou a ser referência no atendimento para outras instituições. 
13-A instituição procura medir a satisfação e percepções dos cidadãos, promovendo RSP feedbacks por meio de uma maior variedade de instrumentos de consulta, e tendo alguém formalmente responsável e treinado em metodologia de pesquisa?

Sim, a OCA tem um canal de manifestações que se apresenta com as seguintes variantes: manifestação escrita, manifestação eletrônica e ouvidoria. Existe a Coordenação de atendimento que está totalmente capacitada para esta função.

a Oca faz um atendimento circunstanciado a pessoas incapacitadas de buscar os serviços nas instalações da Central. Para tanto é disponibilizado uma equipe móvel que se desloca até o local onde o cidadão se encontra, por exemplo: hospital, residência, presídio paro a confecção de alguns serviços.

14-A instituição monitora constantemente a implementação de projetos, fazendo os ajustes necessários?

Sim, há monitoramento constante dos projetos implantados.

15-A instituição busca a transparência, comunicando os resultados obtidos à sociedade, às organizações e a outros departamentos do governo?

Sim, por meio de mídias eletrônicas, mídias sociais e relatórios.

16- Existe um controle estatístico com destaque para serviços mais procurados, assim como os problemas mais comuns e as tratativas adotadas ou previstas?

Sim, o controle é feito constantemente.

1 Manual de Gestão Pública Contemporânea. 2. ed. Atlas, 2009. 


\section{Apêndice A -}

\begin{tabular}{|c|c|c|c|}
\hline Estados & $\begin{array}{c}\text { Nome Fantasia das } \\
\text { Centrais }\end{array}$ & $\begin{array}{c}\text { Data de } \\
\text { Implantação }\end{array}$ & Site \\
\hline Santa Catarina & SACI & $09 / 91$ & \\
\hline Bahia & $\begin{array}{l}\text { Serviços de Atendimento } \\
\text { ao Cidadão / SAC }\end{array}$ & 09/95 & \\
\hline $\begin{array}{l}\text { Rio Grande do } \\
\text { Norte }\end{array}$ & Central do Cidadão & $07 / 97$ & \\
\hline Minas Gerais & PSIU & 09/97 & \\
\hline São Paulo & Poupatempo & $10 / 97$ & \\
\hline Pará & SACI & $11 / 97$ & \\
\hline Ceará & Casa do Cidadão & $01 / 98$ & \\
\hline Maranhão & Shopping Cidadão & 02/98 & \\
\hline Amazonas & $\begin{array}{l}\text { Pronto Atendimento ao } \\
\text { Cidadão / PAC }\end{array}$ & $03 / 98$ & \\
\hline Pernambuco & Expresso Cidadão & 06/98 & \\
\hline $\begin{array}{l}\text { Rio Grande do } \\
\text { Sul }\end{array}$ & $\begin{array}{l}\text { Central de Serviços do } \\
\text { Cidadão }\end{array}$ & 06/98 & \\
\hline Goiás & Vapt-Vupt & $10 / 99$ & \\
\hline $\begin{array}{l}\text { Mato Grosso do } \\
\text { Sul }\end{array}$ & $\begin{array}{l}\text { Central da Cidadania - } \\
\text { Prático }\end{array}$ & $11 / 99$ & \\
\hline Alagoas & $\begin{array}{l}\text { Central de Atendimento } \\
\text { ao Cidadão / JÁ }\end{array}$ & $12 / 00$ & \\
\hline Paraíba & Casa da Cidadania & 03/01 & \\
\hline Rondônia & Shopping do Cidadão & 05/01 & \\
\hline Sergipe & CEAC & 07/01 & \\
\hline Rio de Janeiro & Rio Simples & $10 / 01$ & \\
\hline Amapá & $\begin{array}{l}\text { Central de Atendimento } \\
\text { Popular / CAP }\end{array}$ & $01 / 02$ & \\
\hline Distrito Federal & $\mathrm{Na}$ Hora & 06/02 & \\
\hline Piauí & Espaço Cidadania & $05 / 02$ & \\
\hline Mato Grosso & Ganha Tempo & 04/03 & \\
\hline Vitória-ES & $\begin{array}{l}\text { Centro Integrado da } \\
\text { Cidadania / CIC }\end{array}$ & $10 / 03$ & \\
\hline Acre & $\begin{array}{l}\text { Organização das Centrais } \\
\text { de Atendimento }\end{array}$ & $12 / 10$ & $\begin{array}{l}\text { http://governodoacre- } \\
\text { oca.blogspot.com/ }\end{array}$ \\
\hline
\end{tabular}




\section{ANEXOS}

\section{Anexo A - Política de Atendimento ao Cidadão no Acre}

\section{ESTADO DO ACRE}

\section{DECRETO № 3357, de 20 de Agosto de 2008.}

Institui a Política de Atendimento ao Cidadão para a Administração Pública Estadual e constitui instâncias responsáveis pela sua implementação e acompanhamento.

\section{O GOVERNADOR DO ESTADO DO ACRE,}

NO USO das atribuições que Ihe confere o art. 78, inciso VI, da Constituição Estadual;

Considerando os preceitos contidos no art. $5^{\circ}$ da Constituição Federal;

Considerando a necessidade de estabelecer parâmetros democráticos para que todos os órgãos públicos possam se pautar no relacionamento entre Estado e Cidadão; e

Considerando a premência do uso cada vez mais intensivo de novas soluções para o atendimento público, salvaguardando-se a diversidade sócio-econômica e cultural da população nas várias regiões do Estado,

\section{DE C RE T A:}

\section{CAPÍTULO I}

\section{DOS PRINCÍPIOS E DAS DIRETRIZES DA POLÍTICA DE ATENDIMENTO}

Art. 1 Fica instituída a Política de Atendimento ao Cidadão, com a finalidade de garantir a qualidade e a celeridade na prestação dos serviços, para que o cidadão consiga exercer seu direito à cidadania. 
Art. 2ㅇ O atendimento ao cidadão será prestado com atenção, cortesia e respeito.

Art. 3o A ordem de chegada, salvo no caso dos preferenciais, será rigorosamente obedecida.

Parágrafo único. A ordem de chegada ou de agendamento diz respeito também à seqüência das atividades internas despendidas à devida finalização do atendimento efetuado.

Art. 4 Deverão ser obedecidas às legislações de atendimento preferencial aos idosos, gestantes, mulheres com crianças de colo e a pessoas portadoras de necessidades especiais temporárias e permanentes.

§ 1․ Havendo divergências entre as legislações de diferentes esferas, deverá ser adotada a que for menos restritiva para os cidadãos.

§ 2 A identificação dos cidadãos para encaminhamento ao atendimento preferencial deverá ser feita por observação, procurando-se evitar a solicitação de documentos de comprovação.

Art. 5o É direito de o cidadão obter todas as informações necessárias à todas as etapas do atendimento.

§ 1 Ao cidadão possibilitar-se-á o conhecimento de todo o processo de atendimento.

§ 20 Independente da instituição que prestará outras etapas de atendimento deverá ser informado ao cidadão todos os procedimentos necessários para finalização do serviço solicitado.

Art. 6 Quando necessário o retorno do cidadão para finalização do atendimento ou para retirada de documentos deverá ser fornecido prazo preciso.

Parágrafo único. No caso de ocorrências que impeçam o cumprimento do prazo prometido, as Secretarias e as Instituições Estaduais deverão buscar mecanismos para avisar ao cidadão com antecedência.

Art. 7ํ Nos casos de contingências com impacto no atendimento como paralisações de sistemas, queda de energia, ausência de funcionários, falta de água, ou qualquer 
ocorrência que impeça o atendimento, nenhum cidadão deixará de receber alternativas de atendimento de modo a minimizar possíveis prejuízos.

Art. 8ㅇ Os cidadãos em espera pelo atendimento, em situações normais e em situações de contingência, deverão, quantas vezes for necessário, receber informações e orientações solicitadas.

Art. 9 Todos os serviços devem ter indicadores de tempo médio de atendimento e de espera. Os cidadãos devem ser informados sobre estes prazos, antes de iniciar o atendimento, principalmente nos casos de alta demanda.

Art. 10. Todo cidadão tem direito de acesso às informações sobre os procedimentos exigidos para solicitar os serviços, tais como documentos, requisitos, condições, formulários, custos, prazos e locais de atendimento.

Parágrafo único. Para a democratização do acesso a estas informações, as Secretarias e as Instituições Estaduais deverão utilizar todos os recursos disponíveis de comunicação, de modo que a população otimize seu tempo e custo para a solicitação dos serviços.

Art. 11. Todos os servidores devem solicitar aos cidadãos os mesmos procedimentos e requisitos nas situações iguais de atendimento.

Art. 12. Todos os locais destinados ao atendimento público devem ter avisos afixados, em lugares visíveis, contendo informações sobre os dias e horários de funcionamento. Estas informações e os endereços devem ser amplamente divulgados.

Art. 13. Todo cidadão que chegar até o horário divulgado como sendo o limite para o atendimento, deverá ser atendido e ter o seu atendimento finalizado, conforme a etapa prevista.

Art. 14. Os servidores designados para o atendimento devem ser selecionados de acordo com perfil e capacidade técnica adequados.

Parágrafo único. As Secretarias e Instituições Estaduais deverão criar mecanismos para acompanhar o desempenho destes servidores e promover formação e capacitação continuada. 
Art. 15. As áreas de espera e de atendimento deverão ser acolhedoras, demonstrando preocupação com o bem estar do cidadão.

Art. 16. Os setores e ambientes deverão ser sinalizados adequadamente para facilitar a locomoção dos cidadãos, possibilitando-lhes identificar os locais desejados.

Art. 17. Os folhetos de divulgação dos serviços e dos programas devem estar em locais acessíveis e, quando necessário, servidores devem estar à disposição para prestar informações adicionais.

\section{CAPÍTULO II}

\section{DAS INSTÂNCIAS RESPONSÁVEIS PELA POLÍTICA DE ATENDIMENTO}

Art. 18. Caberá à Diretoria de Organização em Centros de Atendimento - OCA, da Secretaria de Gestão Administrativa, conforme $\S 5^{\circ}$, do art. $2^{\circ}$ do Decreto $\mathrm{n}^{\circ} 1.328 / 2007$, a responsabilidade pela instituição e gerenciamento da política de excelência no atendimento ao cidadão, usuário dos serviços públicos, no âmbito da Administração Pública estadual, mediante o planejamento, a implantação, a coordenação e o gerenciamento de Centros de Atendimento Integrado.

Art. 19. Para a ampliação e incorporação desta Política de Atendimento e de todas as inovações para o conjunto da administração estadual, fica instituído no âmbito do Governo do Estado do Acre, a Rede de Representantes de todos os órgãos, da administração direta e indireta.

Parágrafo único. As atividades a serem desenvolvidas pelos integrantes desta Rede e de que trata este Decreto, ficam sob a orientação da Diretoria de Organização em Centros de Atendimento - OCA.

Art. 20. A Rede de Representantes será composta por 02 (dois) profissionais, sendo um Titular e outro Adjunto, indicados pelos dirigentes das instituições, de acordo com o perfil abaixo estabelecido.

\section{CAPÍTULO III}

DAS ATRIBUIÇÕES GERAIS DOS INTEGRANTES DA REDE DE REPRESENTANTES 
Art. 21. O Representante designado responsabilizar-se-á pela implantação da nova política de atendimento em sua Secretaria e/ou Instituição e pelo monitoramento de sua aplicação, incumbindo-Ihe:

I - participar, juntamente com a Diretoria de Organização em Centros de Atendimento - OCA, de todos os programas, projetos e ações que visem à melhoria da qualidade do atendimento à população no âmbito de sua Secretaria ou Instituição e em todo o governo;

II - manter estreito, sistemático e profícuo relacionamento com todas as atividades relacionadas à prestação de serviços à população, identificando os ajustes a serem feitos;

III - identificar as boas práticas de atendimento e que tenham efetivo resultado para a população; divulgá-las e dar-lhes a configuração de "estudo de caso" para que sejam discutidas e debatidas junto à Rede de Representantes do governo;

IV - criar mecanismos para que os servidores públicos alocados nas atividades de atendimento, possam participar de iniciativas que visem à melhoria dos procedimentos, da desburocratização e da racionalização e da sistemática de atendimento, de acordo com a realidade setorial de cada instituição;

V - manter rigoroso acompanhamento sobre a qualidade das informações prestadas por profissionais de sua Secretaria ou Instituição ao "Sistema Guia do Usuário dos Serviços Públicos", coordenado pela Diretoria OCA; e

VI - participar ativamente em sua Secretaria dos Programas e Projetos da Secretaria de Gestão Administrativa - SGA referentes à modernização administrativa, à melhoria de processos, à desburocratização, à migração dos serviços para o meio eletrônico, ao uso de novas de novas tecnologias de informação e comunicação e que tenham direto impacto na melhoria do relacionamento entre o Estado e a população.

\section{CAPÍTULO IV}

DAS ATRIBUIÇÕES ESPECÍFICAS DOS INTEGRANTES DA REDE DE REPRESENTANTES EM RELAÇÃo AOS CENTROS DE ATENDIMENTO INTEGRADO 
Art. 22. Os Centros de Atendimento Integrado que vierem a ser implantados no Estado do Acre sob responsabilidade da Diretoria OCA/ SGA, poderão contar, além de Secretarias e Instituições do Governo Estadual, com a participação de órgãos da esfera municipal e federal.

Parágrafo único. A participação de outras esferas de governo nas Unidades de Atendimento será formalizada mediante instrumentos legais específicos.

Art. 23. Nos casos de Secretarias ou Instituições do Governo do Estado, caberá aos Representantes as seguintes atribuições específicas:

I - participar do planejamento, da implantação e do acompanhamento da manutenção da qualidade de atendimento nestas Unidades de Atendimento;

II - colaborar para que novas soluções de atendimento público sejam experimentadas nestas Unidades de Atendimento, principalmente àquelas que digam respeito às medidas de simplificação integradas aos procedimentos de outras Instituições e ao uso de multi-canais no relacionamento com a população;

III - propor, de acordo com a realidade setorial de sua Secretaria ou Instituição, alternativas para que a retaguarda operacional esteja em conformidade com as necessidades de funcionamento das Centrais de Atendimento Integrado;

IV - planejar, juntamente com a Diretoria OCA, as ocorrências programadas que tenham direto impacto no atendimento, oferecendo alternativas para que a população não seja prejudicada;

V - manter controle das situações de contingências imprevistas prestando informações e esclarecimentos, de modo que a população tenha conhecimento dos prazos para normalização do atendimento ou de alternativas para reduzir os impactos negativos;

VI - comunicar previamente à Diretoria OCA as alterações nos procedimentos para a realização dos serviços prestados nos Centros de Atendimento Integrado e, com ela, implementar medidas para que a população seja informada com a necessária antecedência; 
VII - manter direto relacionamento com os seus servidores alocados nos Centros de Atendimento Integrado, avaliando-os de acordo com diretrizes e critérios prédefinidos pela Diretoria OCA;

VIII - criar condições e propor a incorporação de inovações experimentadas com êxito nos Centros de Atendimento para a sua Secretaria ou Instituição;

IX - contribuir para que a Rede de Representantes do governo do Estado do Acre seja creditada como instância legítima, responsável pela mudança cultural na prestação de serviços públicos à população.

\section{CAPÍTULO V}

DO PERFIL E DOS REQUISITOS ESSENCIAIS DOS PARTICIPANTES DA REDE DE REPRESENTANTES

Art. 24. Os Representantes Institucionais deverão:

I - ser indicados pelos titulares das Secretarias ou Instituição de acordo com procedimentos e prazos a serem definidos pela Secretaria de Gestão Administrativa;

II - ter representatividade junto a todos os setores de sua Secretaria ou Instituição;

III - ter domínio ou fácil acesso e interlocução com a área de atendimento em todas as suas modalidades: presencial, eletrônico e telefônico;

IV - serem informados com antecedência (preferencialmente ter direta participação) de todas as medidas, ações, programas e projetos com direto impacto no atendimento, em todas as suas modalidades, em desenvolvimento na sua Secretaria ou Instituição;

Parágrafo único. Os nomes dos representantes indicados serão publicados em portaria do Secretário de Estado da Gestão Administrativa.

Art. 26. Este Decreto entra em vigor na data de sua publicação.

Rio Branco-Acre, de de 2008, $120^{\circ}$ da Republica, 106ํำ do Tratado de Petrópolis e $47^{\circ}$ do Estado do Acre.

Arnóbio Marques de Almeida Júnior

Governador do Estado do Acre 